Sabah M. Aman Allah, Nihad Ali Shafeek Abbass and Bassira Kassim Sullayman

\title{
Study the total Stopping Power of electrons in Beryllium
}

\author{
Sabah M. Aman Allah*, Nihad Ali Shafeek Abbass ** and Bassira Kassim Sullayman** \\ *Physics Dept. College of Science - Tikrit University \\ **Physics Dept. College of Education/Tuzkhurmatu -Tikrit University \\ Received 1 March 2016 ; Accepted 11 July 2016
}

\begin{abstract}
$\underline{\text { Abstract }}$
The aim of the present research is calculation the values of total $S_{\text {tot }}$ stopping power which consisted from two parts :radiative $S_{R a d}$, collisional $S_{\text {Coll }}$ of electrons by employing BetheBloch relativistic formula. All the related equations programmed via MathCad2012 by using the mean ionization potential I value for Beryllium in the energy range of $(0.1-10) \mathrm{MeV}$, the results showing a that the collisional stopping power is the dominate along the energy interval of incident electrons than the radiative stopping power and the by comparing the $S_{\text {tot }}$ values of Estar code with present results shows a in excellent agreement in especially in the energies (0.1-3) MeV ,after that, the Bethe-Bloch relativistic formula show some discrepancies, which requires addition another corrections factors to keeps the errors in results small.
\end{abstract}

Keywords: Bethe-Bloch, stopping power, radiative, collision, Beryllium ,mean excitation energy. 
Study the total Stopping Power of electrons in Beryllium

Sabah M. Aman Allah, Nihad Ali Shafeek Abbass and Bassira Kassim Sullayman

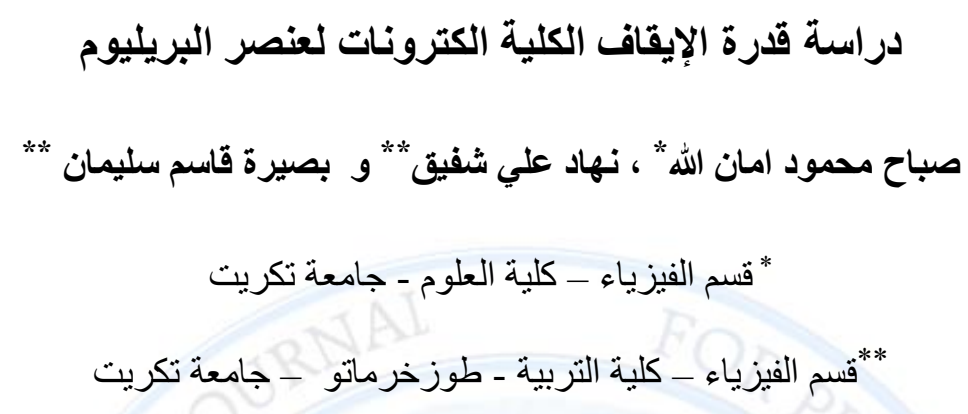

\section{الخلاصة}

ان الهدف من هذا البحث الحسالي هو حســاب قيم قدرة الإيقاف الكلية Stot والمكونـة من جزئيين همـا :قدرة الايقاف

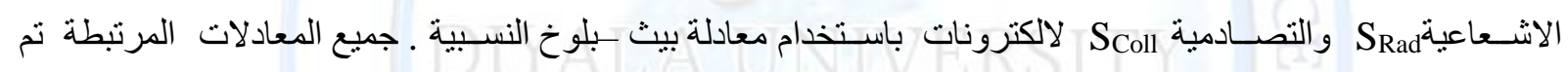
برمجتها وفق البرنامج الحسـابي MathCad2012 باسـتخدام معدل جهد التأيين I لعنصـر البريليوم ولمدى طاقة يبدأ من(0.1 - 10)ميكا إلكترون فولت وقد بينت النتائج التي حصـلنا عليها هيمنة قدرة الإيقاف التصـــادمية اكثر من قدرة

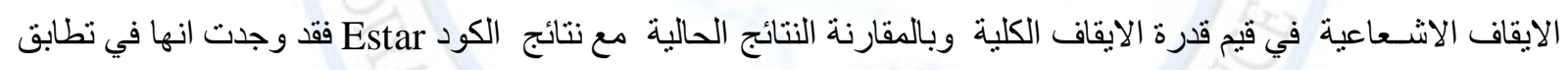

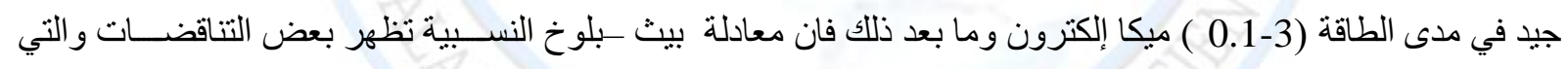

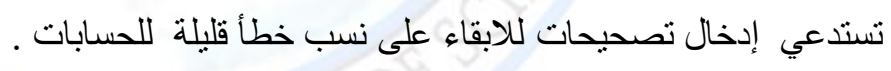
الكلمات المفتاحية: معادلة بيث-بلوخ ، قدرة الايقاف ،الاشعاعية ،التصادمية ،معدل طاقة التأيين، البريليوم . 
Sabah M. Aman Allah, Nihad Ali Shafeek Abbass and Bassira Kassim Sullayman

\section{Introduction}

The Stopping Power (SP) of a medium is a parameter used to describe the gradual loss of the energy of the charged particle [1]. The Study of (SP) of positron and electron through matter is an effective tool for exploring the structure of matter .The importance of SP in variety of applications such as radiation physics, Chemistry ,Biology and Medicine especially for $\beta^{-}$and $\beta^{+}$in matter have widely usage in medical applications [2]. Beryllium is a chemical element with symbol Be and atomic number 4and atomic weight of 12 .The stopping power evaluations for $\beta^{-}$are studied in two different ways : the first is to consider the interactions of incoming of the electron and positron with target electron, which is called collisional stopping power while the second is considered the fact that accelerated charged particles is radiated ,which is called radioactive stopping power or Bremsstrahlung Loss which will discussed in next section in details. The total stopping power for light charged particle is given as following [3]:

$$
S_{\text {tot }}(E)=S_{\text {Coll }}+S_{\text {Rad }}
$$

An extensively study [3-11] exists in the literatures ,Berger and Seltzer [4] had modified the Bethe -Heitler theory and introduced empirical corrections to calculate the mean energy loss by Bremsstrahlung .Btra[10] calculated the stopping power for positron with two parameter approximation and it is valid for positron energy between $1 \mathrm{KeV}-5000 \mathrm{KeV}$, besides its found that there a multiple scattering distribution which exhibits differences between $\beta^{-}$and $\beta^{+}$. Jablonski et al [11] report an improved predictive formula for electron stopping power based on analysis and fit stopping power calculated from the optical data for 37 elements in energy range $200 \mathrm{keVto} 30 \mathrm{keV}$. Zhenya et al [12] studied systematically the stopping power and mean free path in amino acids. The aim of this work is to use this Bethe-Bloch theory in order to determine the $\mathrm{S}_{\text {Coll }}$ of tungsten which is of a huge importance in various applications. 
Sabah M. Aman Allah, Nihad Ali Shafeek Abbass and Bassira Kassim Sullayman

\section{Metholodgy}

The term stopping power can be classified into two types of interactions, namely collisional (with orbital electrons) and radiative (with nucleus) as following:

\section{1-The Collisional Stopping Power S Coll}

$\mathrm{S}_{\mathrm{Coll}}$ is defined as hard collision with atomic electrons, this results in excitation or ionization these ultimately end with rising the temperature of the target (through atomic and molecular vibrations ) unless the ions and electrons can be separated using an electric field as done in radiation detectors. The collisional stopping power of Beta particles is different from the heavy charged particles because of two physical reasons : firstly, an electron can lose a large fraction of its energy in single collision with an atomic electron which has an equal masses ,secondly $\beta^{-}$particle is identical to the atomic electron with which it collides and $\beta^{+}$is electrons antiparticle that in quantum mechanics, the identity of particles implies that one cannot distinguishes experimentally between the incident and struck electron after collision .energy loss is defined in such a way that the electron of lower energy after collision is treated as struck particle unlike heavy charged particles, the identity of $\beta^{-}$particle and the relation of $\beta^{+}$to atomic electrons imposes certain symmetry requirements that described their collisions with atom. The $\mathrm{S}_{\mathrm{Coll}}$ of electron can be written as the following [13]

(2)

$$
-\left(\frac{d E}{d x}\right)_{\text {Coll }}^{ \pm}=\frac{4 \pi r_{e}^{2} m c^{2} n Z}{\beta^{2} A}\left[\ln \frac{m c^{2} \tau \sqrt{\tau+2}}{I \sqrt{2}}+F^{-}(\beta)\right]
$$

Where

$$
F^{-}\left(\beta^{-}\right)=\frac{1-\beta^{2}}{2}\left[1+\frac{\tau^{2}}{8}-(2 \pi+1) \ln 2\right]
$$


Sabah M. Aman Allah, Nihad Ali Shafeek Abbass and Bassira Kassim Sullayman

Equation (3) is a dimensionless functions depending on the energy $\mathrm{E}$ in $\mathrm{MeV}$ of the incident electron, $\beta=\mathrm{v} / \mathrm{c}$ and $\tau=\mathrm{E} / \mathrm{mc}^{2}$ is the kinetic energy of for $\beta^{-}$expressed in multiples of electron rest mass energy $\mathrm{mc}^{2}$ and the other symbols in equation (2) are defined as following:

$r_{e}=$ classical radius of electron.

$\mathrm{E}=$ energy of the incident electron .

$\mathrm{A}$ and $\mathrm{Z}=$ mass and atomic number of target material .

$\mathrm{x}=$ distance traveled by the electron in material.

$\mathrm{I}=$ average excitation potential of target material.

$\mathrm{n}=$ electron density of material which can be calculated by the equation[15]:

$$
\mathrm{n}=\mathrm{N}_{\mathrm{A}} \mathrm{Z} \rho / \mathrm{A} \mathrm{M}_{\mathrm{u}}
$$

Where $\mathrm{N}_{\mathrm{A}}$ is Avogadro's number, $\rho$ density of target material and $\mathrm{M}_{\mathrm{u}}$ is the molar mass constant . In the equation (2), after substitution the above values, we obtain a more simplified formula in units of $\mathrm{MeV} / \mathrm{cm}$ [8].

$$
\left(-\frac{d E}{d x}\right)^{ \pm} \text {Coll }=\frac{5.08 \times 10^{-31} n}{\beta^{2}}\left[\ln \frac{3.61 \times 10^{5} \tau \sqrt{\tau+2}}{I}+F^{-}\left(\beta^{-}\right)\right]
$$

Where $(-\mathrm{dE})$ is the energy increment lost in the infinitesimal material thickness of $\mathrm{dx}$.Hence higher stopping power means shorter range in material that the particle can penetrate. The stopping power is proportional inversely with the incident particle velocity and ionization energy .In the other hand, the mass stopping power of a material is obtained by dividing the stopping power by density .Common units for mass stopping power $-\mathrm{dE} / \mathrm{\rho dx}$ are $\mathrm{MeV} \cdot \mathrm{g}^{-1} \cdot \mathrm{cm}^{2}$ .The mass stopping power is a useful quantity because it expresses the rate of energy loss of charged particle per g. $\mathrm{cm}^{-2}$ of the medium traversed. 
Sabah M. Aman Allah, Nihad Ali Shafeek Abbass and Bassira Kassim Sullayman

\section{2-The Radiative Stopping Power $S_{\text {rad }}$}

The radiative term, $(d E / d x)_{\text {Rad }}$, accounts for the energy loss due to bremsstrahlung, Cerenkov radiation or nuclear interactions S $_{\mathrm{Rad}}$ represent the inelastic collision with nucleus, which produces a quanta of electromagnetic radiation (photon of energy $\mathrm{h} v$ as shown in fig. (1)) by particle which is important for electrons. Bethe and Heitler obtained an approximate relation between the collisional $S_{\text {Coll }}$ and radioactive $S_{\text {Rad }}$ stopping powers by the relation [5].

$$
\text { (6) } S_{\text {Rad }}^{ \pm}=S_{\text {Coll }}^{ \pm}\left(\frac{E Z}{800}\right)
$$

Where the signs (+) and (-) refers to positron and electron respectively, $\mathrm{Z}$ is the atomic number of the target atom and $\mathrm{E}$ is the energy of the incident positron or electron in $\mathrm{MeV}$. By combining the equations (1) and (6) we get [3]:

$$
S_{\text {tot }}=S_{\text {Coll }}^{ \pm}\left(1+\frac{E Z}{800}\right)
$$

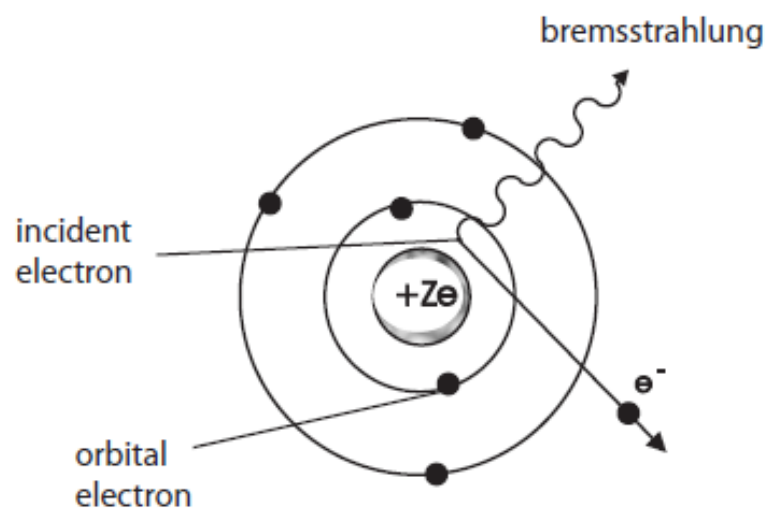

Fig (1): Illustrates the Radiative stopping Power Mechanism which produces Bremsstrahlung radiation. 


\section{Sabah M. Aman Allah, Nihad Ali Shafeek Abbass and Bassira Kassim Sullayman}

\section{3-Mean excitation energies I}

Mean Ionization parameter $I$ of an atom or molecule describes the average minimum amount of energy required to remove an electron from certain electron shell to infinity which measured in eV .A number of semi-empirical [15]:

$$
\begin{array}{rr}
\mathrm{I}=12.0 \mathrm{Z}+7 & \mathrm{Z}<13 \\
\mathrm{I}=9.76 \mathrm{Z}+5.58 \mathrm{Z}^{-0.19} & \mathrm{Z} \geq 13
\end{array}
$$

The mean ionization parameter I is a function of the target atomic number $\mathrm{Z}$.

\section{$\underline{\text { Results and Discussion }}$}

The results of $S_{\text {Coll }}, S_{\text {Rad }}$ and $S_{\text {tot }}$ are illustrated in figures 2,3,4 and table 1 respectively. These results are obtained by application the equations $2-9$ which has been written by program named Mathcad 2012 for Beryllium in the energy range between $(0.1-10) \mathrm{MeV}$. When the electron entered a material, it's not only lost the kinetic energy only, but its directional changes continuously and this particles suffering from many deviations at large angles along its path length after approaches the nuclear field of target atom. The nature of collisional interactions of incident and orbital electrons results from the interactions of the electrical fields of both electrons ,the incident electron as approaches the orbital electrons not an actual contact occurs between them, but it's like the interactions of two similar magnetic poles. The difference between electron incident $\mathrm{E}$ and mean ionization energies I of target atoms represent the energy lost in the interaction $E_{\text {loss }}$ and is given by [14]:

$$
\text { I. } \mathrm{E}_{\mathrm{loss}}=\mathrm{E}-\mathrm{I}
$$

II. The $S_{\text {Rad }}$ values proportional to the incident electron energy $E$ and this situation can be explained that the slow electrons (low energy electron )spend most its time in interactions with orbital electrons and this indicates that these electron has high probability of interactions 


\section{Sabah M. Aman Allah, Nihad Ali Shafeek Abbass and Bassira Kassim Sullayman}

with atomic electrons while the fast electrons has low probability of interactions with these electron and pass over the columbic field without influenced by the electrons, thus this induced the electrons to open more channels of radiative energy losses. When we compare the results of both $S_{\text {Coll }}$ and $S_{\text {Rad }}$, we found that that the $S_{\text {Coll }}$ dominates over the $S_{\text {Rad }}$ due to the low energy range and the most contribution in $S_{\text {tot }}$ is due to it. In all figures, we observe a divergence of present results and Estar, after $\mathrm{E}=3 \mathrm{MeV}$, this is may be due to that Bethe-Bloch relativistic formula used in calculations required some corrections such as density and shells .

\section{Conclusions}

The present calculations refers to that the $S_{\text {tot }}$ decreases with increasing particle incident energies. With increasing particle incident energies, $S_{\text {Rad }}$ values increasing due to the electrons approaches the nuclear field of target atom and production the Bremsstrahlung .The most dominant interaction of the incident electrons at low energies with the valence electrons of $\mathrm{Be}$ is the radiative $S_{\text {Rad }}$ while for higher energies is collisional $S_{\text {Coll }}$, hard or soft . The $S_{\text {tot }}$ values mostly produced from the collisional stopping power especially at low energies and SRad has the biggest influence .In other words,

$$
S_{\text {tot }}=S_{\text {Rad }}+S_{\text {Coll }} \approx S_{\text {Coll }}
$$

Finally $\mathrm{S}_{\text {tot }}$ values depends on mass, atomic number $\mathrm{Z}$ and density of the target material. 
Study the total Stopping Power of electrons in Beryllium

Sabah M. Aman Allah, Nihad Ali Shafeek Abbass and Bassira Kassim Sullayman

Table (2): The comparison of the present work collisional and Estar stopping power values of Be.

\begin{tabular}{|c|c|c|c|c|c|c|}
\hline $\begin{array}{l}\text { Electron energy } \\
\text { E(MeV) }\end{array}$ & $\begin{array}{l}\mathbf{S}_{\text {Coll }-p . w} \\
\left(\mathrm{MeV}-\mathrm{cm}^{2} / \mathrm{g}\right)\end{array}$ & $\begin{array}{l}\text { S }_{\text {Coll }}-\text { Estar } \\
\left(\mathrm{MeV}-\mathrm{cm}^{2} / \mathrm{g}\right)\end{array}$ & $\begin{array}{l}S_{\text {Rad }}-\mathbf{p} . w \\
\left(\mathrm{MeV}-\mathrm{cm}^{2} / \mathrm{g}\right)\end{array}$ & $\begin{array}{l}\text { S Rad }_{\text {Restar }} \\
\left(\mathrm{MeV}-\mathrm{cm}^{2} / \mathrm{g}\right)\end{array}$ & Total-p.w & $\begin{array}{l}\text { Total- } \\
\text { Estar }\end{array}$ \\
\hline 0.100 & 3.2666 & 3.36 & 0.002 & $2.01 \mathrm{E}-03$ & 3.2686 & 3.36 \\
\hline 0.125 & 2.8634 & 2.93 & 0.0021 & 2.09E-03 & 2.8655 & 2.93 \\
\hline 0.150 & 2.5908 & 2.63 & 0.0022 & $2.16 \mathrm{E}-03$ & 2.593 & 2.64 \\
\hline 0.175 & 2.3948 & 2.42 & 0.0024 & $2.24 \mathrm{E}-03$ & 2.3972 & 2.43 \\
\hline 0.200 & 2.2477 & 2.27 & 0.0025 & $2.33 \mathrm{E}-03$ & 2.2502 & 2.27 \\
\hline 0.250 & 2.0429 & 2.05 & 0.0028 & $2.51 \mathrm{E}-03$ & 2.0457 & 2.05 \\
\hline 0.300 & 1.9088 & 1.90 & 0.003 & $2.70 \mathrm{E}-03$ & 1.9118 & 1.90 \\
\hline 0.350 & 1.8156 & 1.8 & 0.0032 & $2.91 \mathrm{E}-03$ & 1.8188 & 1.80 \\
\hline 0.400 & 1.7482 & 1.73 & 0.0033 & $3.14 \mathrm{E}-03$ & 1.7515 & 1.73 \\
\hline 0.450 & 1.698 & 1.67 & 0.0034 & 3.37E-03 & 1.7014 & 1.67 \\
\hline 0.500 & 1.6597 & 1.63 & 0.0035 & $3.62 \mathrm{E}-03$ & 1.6632 & 1.63 \\
\hline 0.550 & 1.6301 & 1.59 & 0.0038 & $3.88 \mathrm{E}-03$ & 1.6339 & 1.60 \\
\hline 0.600 & 1.607 & 1.57 & 0.0043 & $4.14 \mathrm{E}-03$ & 1.6113 & 1.57 \\
\hline 0.700 & 1.5742 & 1.53 & 0.0047 & $4.69 \mathrm{E}-03$ & 1.5789 & 1.53 \\
\hline 0.800 & 1.5536 & 1.50 & 0.0052 & $5.28 \mathrm{E}-03$ & 1.5588 & 1.51 \\
\hline 0.900 & 1.5407 & 1.59 & 0.0056 & 5.89E-03 & 1.5463 & 1.49 \\
\hline 1.000 & 1.533 & 1.57 & 0.0069 & $6.52 \mathrm{E}-03$ & 1.5399 & 1.48 \\
\hline 1.25 & 1.5272 & 1.53 & 0.0084 & $8.20 \mathrm{E}-03$ & 1.5356 & 1.46 \\
\hline 1.5 & 1.5314 & 1.50 & 0.0101 & $1.00 \mathrm{E}-02$ & 1.5415 & 1.47 \\
\hline 1.75 & 1.5402 & 1.45 & 0.0117 & $1.19 \mathrm{E}-02$ & 1.5519 & 1.48 \\
\hline 2.00 & 1.5512 & 1.45 & 0.0151 & 1.39E-02 & 1.5663 & 1.50 \\
\hline 2.5 & 1.5751 & 1.46 & 0.0187 & $1.81 \mathrm{E}-02$ & 1.5938 & 1.52 \\
\hline 3.00 & 1.599 & 1.47 & 0.0229 & $2.25 \mathrm{E}-02$ & 1.6219 & 1.53 \\
\hline 3.50 & 1.6216 & 1.48 & 0.0269 & $2.71 \mathrm{E}-02$ & 1.6485 & 1.55 \\
\hline
\end{tabular}




\section{DIYALA JOURNAL FOR PURE SCIENCES}

Study the total Stopping Power of electrons in Beryllium

Sabah M. Aman Allah, Nihad Ali Shafeek Abbass and Bassira Kassim Sullayman

\begin{tabular}{|c|c|c|c|c|c|c|}
\hline 4.0 & 1.6425 & 1.49 & 0.0311 & $3.18 \mathrm{E}-02$ & 1.6736 & 1.56 \\
\hline 4.50 & 1.662 & 1.50 & 0.0349 & $3.67 \mathrm{E}-02$ & 1.6969 & 1.57 \\
\hline 5.0 & 1.68 & 1.51 & 0.0392 & $4.17 \mathrm{E}-02$ & 1.7192 & 1.58 \\
\hline 5.5 & 1.6968 & 1.52 & 0.0423 & $4.69 \mathrm{E}-02$ & 1.7401 & 1.61 \\
\hline 6.0 & 1.7124 & 1.53 & 0.046 & $5.21 \mathrm{E}-02$ & 1.7646 & 1.63 \\
\hline 7.0 & 1.7407 & 1.54 & 0.0536 & $6.28 \mathrm{E}-02$ & 1.7943 & 1.65 \\
\hline 8.0 & 1.7657 & 1.56 & 0.0618 & $7.39 \mathrm{E}-02$ & 1.8275 & 1.67 \\
\hline 9.0 & 1.7882 & 1.56 & 0.0709 & $8.51 \mathrm{E}-02$ & 1.8591 & 1.71 \\
\hline 10 & 1.8085 & 1.57 & 0.0783 & $9.66 \mathrm{E}-02$ & 1.8868 & 1.73 \\
\hline
\end{tabular}

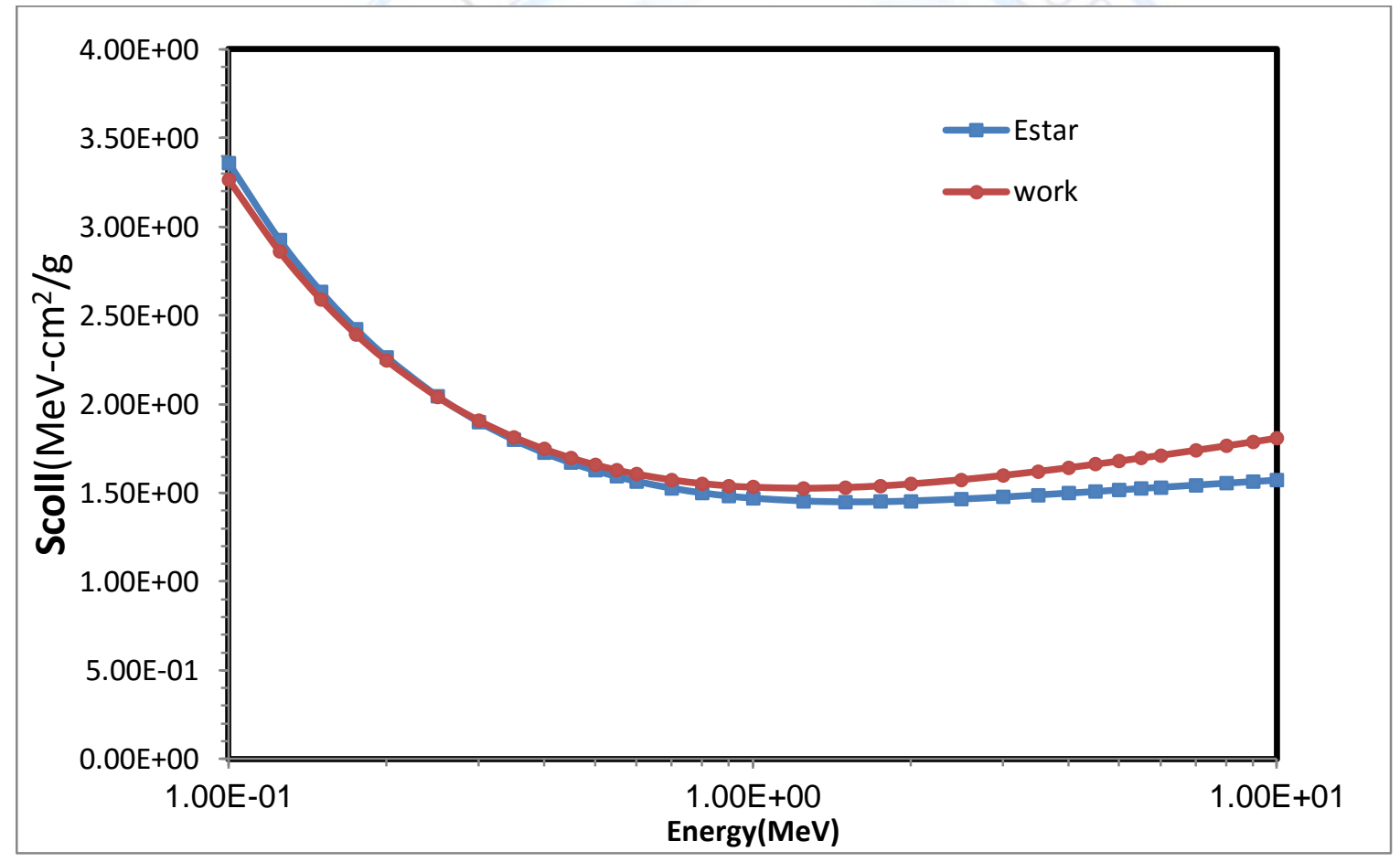

Fig.(2)Comparison of the present work and Estar results for collisional stopping power of electrons in the element $\mathrm{Be}$. 


\section{DIYALA JOURNAL FOR PURE SCIENCES}

Study the total Stopping Power of electrons in Beryllium

Sabah M. Aman Allah, Nihad Ali Shafeek Abbass and Bassira Kassim Sullayman

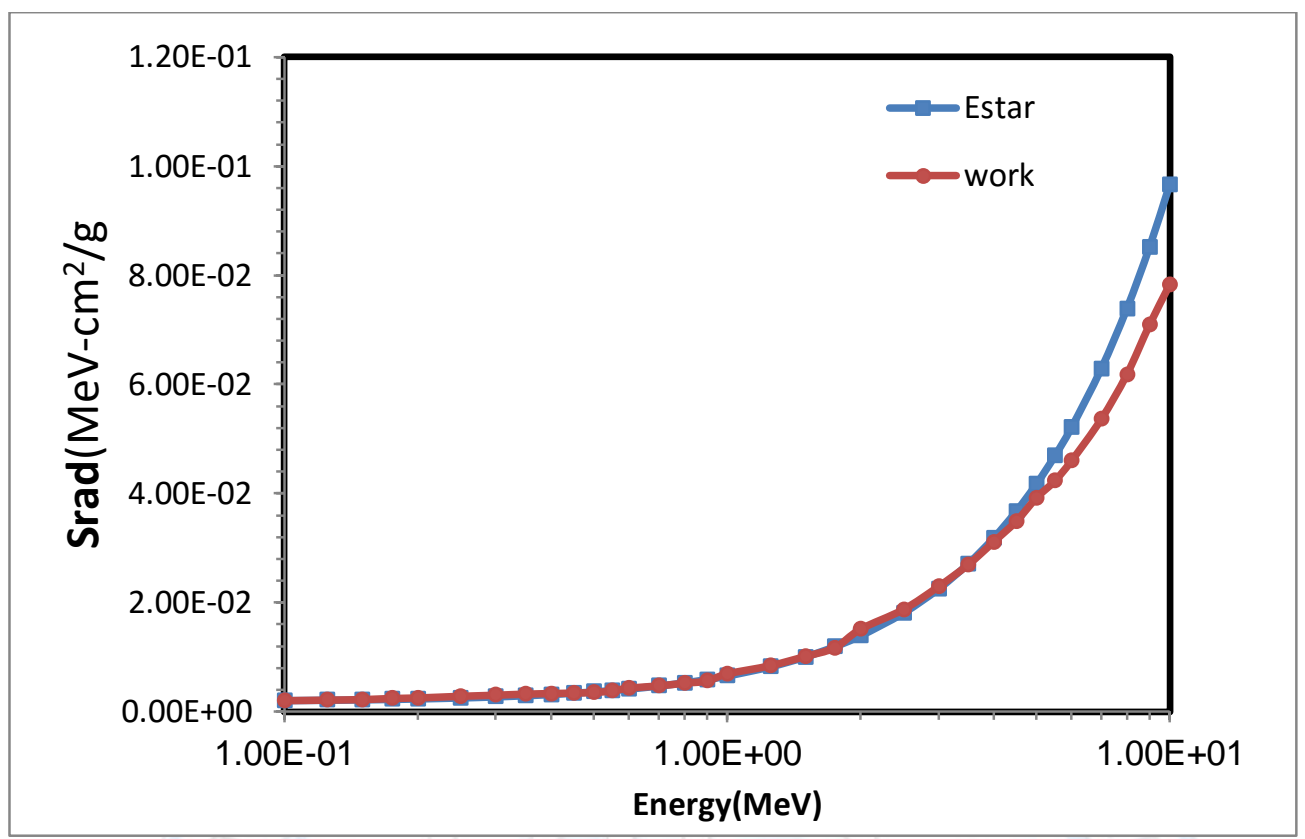

Fig.(3)Comparison of the present work and Estar results for radiative stopping power of electrons in the element $\mathrm{Be}$.

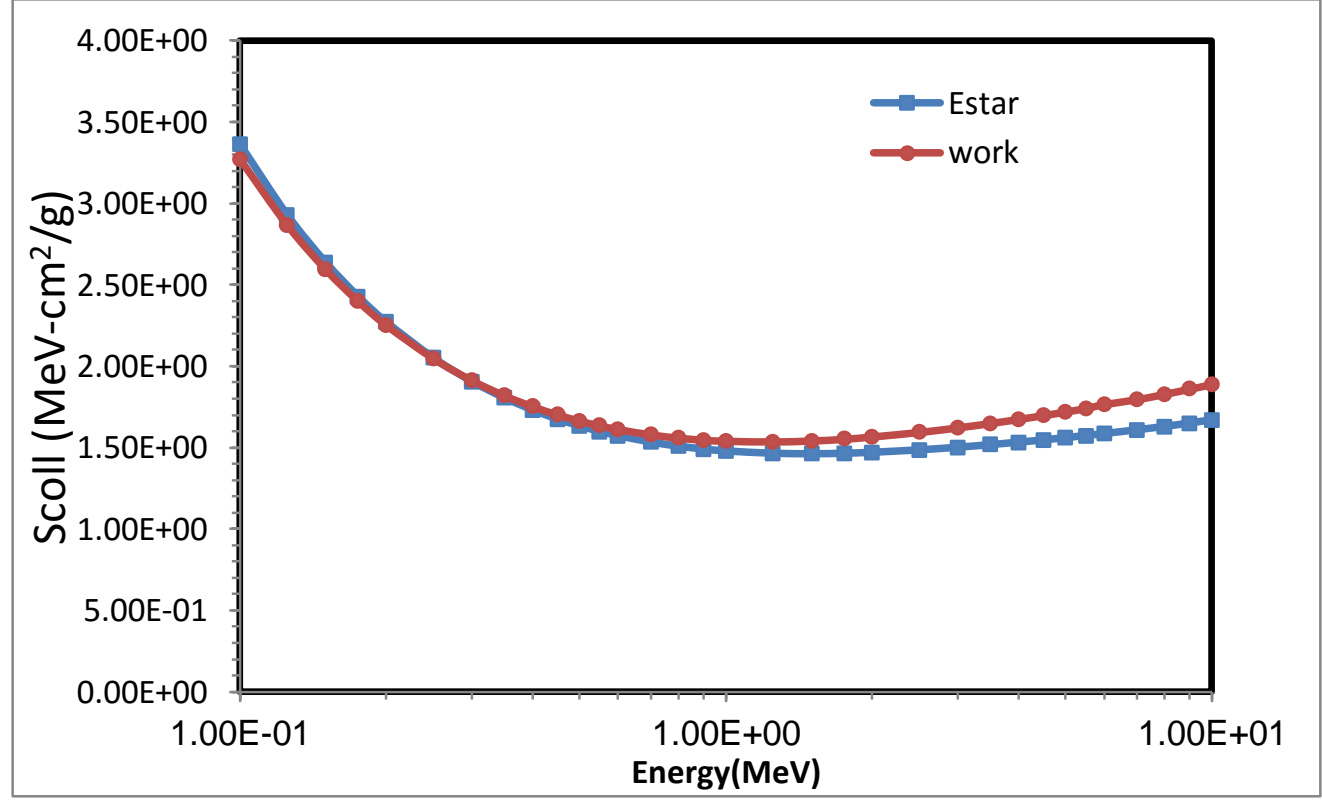

Fig. (4)Comparison of the present work and Estar results for total stopping power of electrons in the element Be. 
Sabah M. Aman Allah, Nihad Ali Shafeek Abbass and Bassira Kassim Sullayman

\section{$\underline{\text { References }}$}

1. E.B.Podgorsak "Radiation physics for medical physicists " Ch.6 p.22 SpringerVerlag Berlin Heidelberg, (2010).

2. Mustafa Cagatay Tufan and Hasan Gumus " A study on the calculation of stopping power and CSDA range for incident positrons " journal of nuclear material 412 p.308314(2011).

3. P.B.Pal, V.P. Varshney and D.K.Gupta -"Semiempircal stopping power equation for positrons "Journal of applied physics 60 (1986).

4. M. J. Berger, S. M. Seltzer," Stopping powers and ranges of electrons and positrons" (National Bureau of Standards Report, NBSIR 82-2550 A, (1982).

5. H. A.Bethe, Z. Phys.76, p.293 (1932).

6. C.Moler, Ann.Phys. 14, p.568 (1932).

7. H.J. Bhabha,Proc,R.Soc.London Ser A. p.154 -194 (1936).

8. F.Fohrlch and B.C Carlson, Phys. Rev. 93, 38(1953).

9. H. Bethe and W. Heitler, Proc R.Soc London A .146,83 (1934).

10. R.K.Btra and M.L. Sehgal ,Nucl.Phys. A.156 ,314 (1970).

11. A.Jablonski, S.Tanuma and C.J. Powell " modified predicative formula for electron stopping power "J.Applied physics p. 103 (2006).

12. Zhenyu Tan ,Yueyuan Xia, Mingwmino . Zhao and Xian gdong Liu " Electron stopping power and inelastic mean free path in a acids and protein over energy range 20$20 \mathrm{KeV}$ " Rad. Biophysics p. 450 vol.45 (2008).

13. ICRU "Stopping powers for electrons and positrons. (International Commission on Radiation Units and Measurements" Bethesda, MD Report No. 37, 1984.

14. Kenth Krane " Modern Physics 2nd edition " Ch. 5 p.145 John Wiley \& sons Inc USA(1996) .

15. Mustafa Cagatay Tufan,Onder Kabaday and Hasan Gumus "Calculation of the stopping power for intermediate energy positrons " Chinese Journal of physics vol.44, No.4p.(290-296), China (2006). 